Escuela de Ciencias Sociales y Humanidades, UNED, C.R.

URL: http://investiga.uned.ac.cr/revistas/index.php/espiga/index

ISSN: $1409-4002 \cdot$ e-ISSN: 2215-454X

\title{
El estudio del crimen desde la mirada crítica de Baratta
}

\section{Johnny Valverde-Chavarría*}

iD https://orcid.org/0000-0003-4476-4005

Recibido: 08 de mayo, 2019 - Aceptado: 30 de mayo, 2019

\section{RESUMEN}

En este artículo se pretende acercar al lector a la mirada crítica que tiene el criminólogo italiano Alessandro Baratta sobre el crimen, la criminalidad y el criminal. Sucintamente se desarrollan los principales postulados que expone el autor sobre la temática en una de sus principales obras: Criminología crítica y crítica al derecho penal. Introducción a la sociología jurídico-penal.

Palabras clave: Derecho penal, criminología, defensa social, conducta criminal.

\section{Introducción}

Corresponde a la sociedad, representada en el Estado y sus instituciones, definir estrategias políticas y legales para la atención del fenómeno delincuencial en sus múltiples manifestaciones: desde el hurto más simple hasta la complejidad de la delincuencia organizada en el ámbito institucional público (delitos de «cuello blanco»), pasando por el tráfico de drogas, grupos delictivos, contrabandistas, sicariato, estafadores, entre muchas otras.

Formato de citación según APA

Valverde Chavarría, J. (2019). El estudio del crimen desde la mirada crítica de Baratta. Revista Espiga, 18 (38), 133-140.

\section{Formato de citación según Chicago-Deusto}

Valverde Chavarría, Johnny (2019). «El estudio del crimen desde la mirada crítica de Baratta». Revista Espiga 18, n. ${ }^{\circ} 38$ (julio-diciembre, 2019): 133-140.

* Asesor Académico del Sistema de Estudios de Posgrado, Universidad Estatal a Distancia (UNED). Doctor en Educación por la UNED, Costa Rica. Correo: jvalverde@uned.ac.cr 
Este artículo se propone responder, desde la mirada crítica de Alessandro Baratta, lo siguiente: ¿Cómo comprender estas dinámicas del delito, su persecución y castigo desde un enfoque teórico sustentado en el análisis de la multivariabilidad del fenómeno?

El estudio de la criminalidad, realizado por el abogado y sociólogo italiano Alessandro Baratta (1933-2002) en su libro de 1982, Criminología crítica y crítica al derecho penal. Introducción a la sociología jurídico-penal, orienta a una comprensión de la criminalidad y de la persona criminal en el marco social e histórico que hace posible la aparición del derecho penal burgués y sus consecuencias, para calificar el delito y establecer las penas que quien delinque recibe; también, en esta publicación, se encuentra una alternativa jurídica a tal visión de la criminalidad, con la introducción del «modelo del etiquetamiento o de la reacción social».

Con su libro, Baratta ofrece un marco referencial más comprensivo que a la vez permite sopesar críticamente el enfoque de «defensa social» generado en el Estado burgués, lo cual, según el autor, nace con el advenimiento del Estado burgués, luego de la Revolución francesa.

La «defensa social» consiste en reconocer las causas de la criminalidad como medio para controlar el funcionamiento del sistema social, con instrumentos legales sustentados en la persecución y el castigo del delito.

En palabras de Berducidoํㅡ en un artículo publicado en su blog, para la teoría de la defensa social

«la meta codiciada no debe ser el castigo del delincuente, sino la protección eficaz de la sociedad a través de estrategias, no necesariamente penales, que partan del conocimiento científico de la personalidad de aquél y sean capaces de neutralizar su eventual peligrosidad de modo humanitario e individualizado».

En la base de este proceso se encuentra el derecho penal como manto jurídico que cubre la protección del conglomerado social y que se sostiene en los siguientes principios:

- de igualdad,

- de legitimidad,

- de culpabilidad,

- del bien y del mal,

- del fin o de la prevención, y

- del interés social y de delito natural.

Cada uno explicado desde una óptica que permite al sistema social reaccionar ante la conducta criminal (desviación) de sus individuos.

Según Reyes, citado por Cermeño²,

1. Berducido Mendoza, Héctor Eduardo, El origen de la criminología científica (p. 17), acceso: 09 de julio, 2019, https://hectorberducido.files.wordpress.com/2008/04/el-origen-de-la-criminologia-cientifica.pdf

2. Cermeño, Raúl, «Relaciones de la criminología con otras ciencias» (párrafo 5, 2010), acceso: 09 de julio, 2019, http://criminologiaumg.blogspot.com/ 
«para el Derecho Penal solo es delito aquella especie de conducta que en razón de una supuesta o real antisocialidad, el legislador ha considerado necesario recoger en una norma positiva y adscribirle una sanción (Nullum crimen nulla poena sine lege. Ningún crimen, ninguna pena sin ley)».

En contraposición, Baratta propone una aproximación crítica al fenómeno de la criminalidad que considere factores de carácter social e histórico, que permita superar el «análisis del fenómeno criminal desde el sujeto criminal hacia el sistema penal y hacia los procesos de criminalización que de él forman parte...» $»^{3}$.

A tal mirada particular la denomina «modelo del etiquetamiento o de la reacción social $»^{4}$ (en inglés, labelling approach), está sustentada en teorías criminológicas que forman parte de la criminología crítica y que se generan en corrientes sociológicas de origen fenomenológico como el interaccionismo simbólico y el etnometodológico; así como en la sociología de la desviación y del control social y «de otros desarrollos de la reflexión sociológica e histórica sobre el fenómeno criminal y sobre el derecho penal» ${ }^{5}$.

El foco de atención de la criminología crítica se pone, entonces, en atribuir menos, al individuo, las causas que originan el comportamiento criminal y más bien en analizar las condiciones sociales que propician el etiquetamiento de «criminal» al comportamiento de ciertos sujetos en la sociedad y no de otros, también en comprender cómo funciona la reacción social e institucional ante tales hechos, lo que Baratta denomina «proceso de criminalización».

Lo anterior supone un cambio de paradigma en la atención de la criminalidad; puesto que, en opinión del autor, el derecho penal propio del Estado burgués

«contribuye a asegurar, reproducir y aun legitimar (esto último es una función esencial para el mecanismo de reproducción de la realidad social) las relaciones de desigualdad que caracterizan a nuestra sociedad, en particular la escala social vertical, es decir la distribución diversa de recursos y de poder...» $\nu^{6}$.

En tanto, la introducción del labelling approach para la investigación criminológica conlleva necesariamente a definir una política criminal alternativa que pone el acento en las condiciones particulares en que se producen los hechos criminales, ya sean estas de carácter social, cultural o político, así como en el funcionamiento del sistema penal que reacciona ante la criminalidad.

Por ello, la riqueza del enfoque estriba en que las preguntas elaboradas interroguen más a las condiciones que propician la criminalización y la elaboración de las reglas para penalizar o despenalizar la conducta de los individuos y su aplicación que a las causas de la criminalidad.

3. Baratta, Criminología crítica ..., 44 .

4. Ibíd, 44 .

5. Ibíd, 85

6. Ibíd, 85 . 


\section{Psicoanálisis y su aporte a la criminología}

Baratta expone sobre cómo las teorías de la criminalidad se apoyan en una perspectiva psicoanalítica, en particular la del psicólogo austriaco Sigmund Freud, quien traslada el concepto de neurosis al campo de la criminalidad, esta indica que el individuo neurótico reprime sus instintos delictivos gracias a la acción del superyó; mas eso no significa que no los tenga, sino que quedan en el inconsciente, acompañados de un sentimiento de culpa ${ }^{7}$.

El comportamiento delictivo es, según Freud, la superación del sentimiento de culpa como mecanismo de confesión.

Por su lado, otro psicoanalista austriaco, Theodor Reik, señala que en el derecho penal, la pena es para el individuo, la satisfacción de la necesidad inconsciente del castigo por sus actos prohibidos; pero que también sirve a la sociedad en cuanto ella se identifica con el delincuente y necesita ser castigada. Ambas situaciones, dice Reik, «hunden sus raíces en el inconsciente de la psiquis humana» ${ }^{8}$.

En esta línea de pensamiento, Reik examina el perfil psicológico de delincuentes y sostiene que, debido a la culpa inconsciente, los delincuentes a menudo dejan pruebas que pueden llevar a su identificación y detención.

Otros psicoanalistas que contribuyen con las teorías sobre la criminalidad son el médico Franz Alexander y el jurista Hugo Staub, quienes, a diferencia de Freud -que establece su principio «de la identidad de los impulsos que mueven al delincuente y a la sociedad en su reacción punitiva»- ${ }^{9}$ contraponen a ese principio las características psicológicas del mundo de los delincuentes y de quienes representan los organismos del sistema penal.

Exponen que cuando el delincuente recibe una pena, lo que hace es contrabalancear la presión de los impulsos reprimidos, pues cuando los libera, lo que se genera es su fortalecimiento ${ }^{10}$.

Paul Reiwald, criminólogo y jurista alemán, introduce los conceptos de proyección y de chivo expiatorio para explicar cómo la sociedad carga sus sentimientos de culpa en las minorías y grupos marginales de la sociedad, además de proyectar en el delincuente, las tendencias criminales, más o menos inconscientes, quien sirve de chivo expiatorio para la sociedad ${ }^{11}$.

Baratta concluye indicando que, pese a que las teorías psicoanalíticas de la criminalidad son críticas frente a la ideología de la defensa social, «es menester decir que no han logrado superar los límites fundamentales de la criminología tradicional» ${ }^{12}$, en tanto no considera en su análisis la determinación histórica de las relaciones de carácter social y económico que les son inherentes.

\footnotetext{
7. Ibíd, 86 .

8. Ibíd, 46

9. Ibíd, 48 .

10. Ibíd, 48.

11. Ibíd, 49 .

12. Ibíd, 53 .
} 
La teoría estructural-funcionalista, desarrollada por el filósofo y sociólogo francés Émile Durkheim, afirma que el comportamiento delincuencial tiene una base de normalidad en la sociedad y que por ello no hay que buscar sus causas en factores de tipo bioantropológico, natural o situaciones patológicas ${ }^{13}$.

Para el estructural-funcionalismo, el fenómeno de la desviación solo será negativo para la sociedad cuando haya sobrepasado ciertos límites; por ello, el comportamiento delictivo «es un factor necesario y útil del equilibrio y del desarrollo sociocultural» ${ }^{14} \mathrm{y}$ forma parte de la vida social «aunque repugnante, debido a la irreductible maldad humana ${ }^{15}$ ».

Robert K. Merton, sociólogo funcionalista norteamericano, propuso que el comportamiento desviado es tan normal en la sociedad como lo es aquel consonante con las reglas y los valores predominantes ${ }^{16}$; es producto de la falta de relación entre lo que socialmente se considera válido y la posibilidad de los individuos por alcanzarlo lo que origina comportamientos desviados en estos, estimulados además por «los contactos específicos a los cuales está expuesto el sujeto en su ambiente social y profesional» ${ }^{17}$.

En esta línea de pensamiento, Merton reconoce que hay una clase de personas de negocios que se constituye en «ampliamente desviada pero escasamente perseguida»y que denomina «la criminalidad de cuello blanco» ${ }^{18}$.

Sin embargo, Baratta critica que Merton menciona este fenómeno criminal sin profundizar en las causas socioeconómicas que lo posibilitan (ser parte de grupos económicamente más favorecidos en un sistema económico capitalista), sirviéndole de sustento para explicar, de manera superficial, la criminalidad de los estratos más bajos y así consolidar «la imagen tradicional de la criminalidad como propia del comportamiento y del estatus típico de las clases pobres en nuestra sociedad y el correspondiente reclutamiento efectivo de la 'población criminal' de entre estas clases» ${ }^{19}$.

\section{Labelling approach como paradigma criminológico}

Baratta recapitula las teorías examinadas a lo largo de su libro, al mencionar que estas sirven como alternativa crítica a la relación que hace la criminología tradicional entre delincuencia y valores; es decir, al acento que esta pone en «las características particulares que distinguen la socialización y los defectos de socialización a los cuales están expuestos muchos de los individuos que llegan a ser delincuentes ${ }^{20}$.

\footnotetext{
13. Ibid, 55

14. Ibíd, 56 .

15. Ibíd, 57.

16. Ibíd, 59 .

17. Ibíd, 60 .

18. Ibíd, 64 .

19. Ibíd, 65

20. Ibíd, 83 .
} 


\section{El autor enuncia entonces que}

«es imposible comprender la criminalidad si no se estudia la acción del sistema penal que la define y que reacciona contra ella, comenzando por las normas abstractas hasta llegar a la acción de las instancias oficiales (policía, jueces, instituciones penitenciarias que la aplican)» ${ }^{21}$.

De ahí que la criminología basada en el enfoque de la reacción social sustenta su quehacer, como se dijo anteriormente, en el análisis de los procesos de criminalización que forman parte del sistema penal y en todo el sistema de reacción social ante la desviación $^{22}$; definiéndolo por ello como el problema central en el estudio de la validez de los juicios emitidos para atribuirle la calidad de desviado a un comportamiento o a un sujeto y sobre el cual se aplican procesos de criminalización ${ }^{23}$.

Desde la perspectiva del labelling approach, la sociología criminal realiza una aproximación al tema de la criminalidad que supone un cambio de enfoque, ya que pone el énfasis en la «construcción de una teoría materialista, es decir, económico-política, de la desviación, de los comportamientos socialmente negativos y de la criminalización, un trabajo que tiene en cuenta instrumentos conceptuales e hipótesis elaboradas en el ámbito del marxismo... $»^{24}$.

Con ello se inaugura el paso hacia una criminología crítica, lo cual supone para el criminólogo el observar las «condiciones objetivas, estructurales y funcionales, que se hallan en el origen de los fenómenos de la desviación...»; es decir, «los mecanismos mediante los cuales se crean y aplican definiciones de desviación y de criminalidad, y se realizan procesos de criminalización $»^{25}$.

De ello se deriva que a la criminología crítica le interese poner en primer plano las estructuras sociales y su relación con el desarrollo de las relaciones de producción y distribución, como fundamento del análisis del comportamiento desviado ${ }^{26}$.

A su vez, la criminología crítica observa el derecho penal como un mecanismo de control social ejercido durante tres momentos ${ }^{27}$ :

- El de la producción de las normas (criminalización primaria);

- el de la aplicación de las normas, es decir, el proceso penal que comprende la acción de los organismos de averiguación y que culmina con el juicio (criminalización secundaria), y, finalmente,

- el de la ejecución de la pena o de las medidas de seguridad.

En torno a la ejecución de la pena, Baratta señala que contrario al deseo de reinserción social y reeducación que está en la base del sistema carcelario, en las sociedades capitalistas actuales lo que se propicia es más bien devolver al desviado a la población criminal.

\footnotetext{
21. Ibíd, 84 .

22. Ibíd, 234.

23. Ibíd, 166.

24. Ibíd, 165.

25. Ibíd, 166.

26. Ibíd, 166 .

27. Ibíd, 168 .
} 
Opuesto al postulado de la educación de promover en las personas la libertad, el auto respeto y la individualidad, la cárcel «despoja al encarcelado hasta de los símbolos exteriores de la propia autonomía (la vestimenta y los objetos personales)» y «como universo disciplinario, tiene un carácter represivo y uniformante» ${ }^{28}$.

En opinión del autor, en la cárcel el individuo es sometido a un proceso de socialización «que ninguna técnica psicoterapéutica y pedagógica logra volver a equilibrar ${ }^{29} »$; cuanto más tiempo pase en prisión una persona, más efectos negativos habrá sobre la psique, según lo han demostrado exámenes clínicos realizados con test de personalidad.

Tales estudios concluyen que «la posibilidad de transformar un delincuente violento asocial en un individuo adaptable a través de una larga pena carcelaria no parece existir»; y que «el instituto penal no puede realizar su objetivo como institución educativa ${ }^{30} »$.

Baratta concluye lapidariamente que:

«Antes de hablar de educación y de reinserción es, pues, menester hacer un examen del sistema de valores y de modelos de comportamiento presentes en la sociedad en que se quiere reinsertar al detenido. Tal examen no puede, creemos, sino llevar a la conclusión de que la verdadera reeducación debería comenzar por la sociedad antes que por el condenado» ${ }^{31}$.

Para el autor, entonces, el corpus teórico de la criminología crítica hace recaer la atención en el proceso de criminalización, en la medida en que este forma parte sustantiva de las relaciones sociales de desigualdad inherentes a la sociedad capitalista y que sobre este sienta sus bases del derecho penal.

Por ello, expone que

«sólo un análisis radical de los mecanismos y de las funciones reales del sistema penal en la sociedad capitalista tardía puede permitir una estrategia autónoma y alternativa en el sector del control social de la desviación, esto es, una política criminal de las clases actualmente subalternas» ${ }^{32}$.

Para Baratta, el resultado final de tal análisis estriba en la superación del sistema penal característico de la sociedad capitalista.

\section{Conclusiones}

La lectura del libro de Alessandro Baratta, Criminología crítica y crítica al derecho penal, permite comprender las particularidades de la política criminal en las sociedades capitalistas contemporáneas y sus ramificaciones en el tejido social, sobre el cual ajusta los procesos de criminalización, desde la tipificación del delito hasta el castigo que este acarrea, pasando por los mecanismos de persecución del delincuente.

\footnotetext{
28. Ibíd, 194.

29. Ibíd, 194.

30. Ibíd, 194.

31. Ibíd, 194.

32. Ibíd, 209.
} 
Baratta puntualiza que no es posible comprender la criminalidad si no se estudia la acción del sistema penal que la define y que reacciona contra ella, comenzando por las normas que dicta hasta llegar a la acción de las instancias oficiales que las aplican, tales como la policía, los jueces y las instituciones penitenciarias.

Para ello, el estudio del derecho penal burgués permite desentrañar su íntima correspondencia con el modo en que funciona el sistema social y cultural en el que se origina, también cómo este sistema apuntala las condiciones para su propio funcionamiento, con la cárcel como el lugar donde se materializa lo punitivo del orden social.

Baratta subraya en la importancia de que el análisis del fenómeno de la criminalidad recurra a teorías psicoanalíticas, la teoría estructural-funcionalista (que estudia la conducta desviada y la anomia), a la sociología jurídica, entre otras aproximaciones teóricas, es lo que permitirá ampliar la mirada crítica en su estudio, dada la multivariabilidad que le es propia.

\section{ABSTRACT}

\section{A study of crime from the critical stance of Baratta}

This article aims to acquaint the reader with the critical stance on crime, criminality and the criminal from Italian criminologist Alessandro Baratta. His major claims, as developed in one of his main books, Critical criminology and criticism of criminal law, are succinctly exposed.

Key words: Criminal law, criminology, social defense, criminal behaviour.

\section{RÉSUMÉ}

\section{L'étude du crime dès la perspective critique de Baratta}

Cet article vise à approcher le lecteur à la perspective critique sur le crime, la criminalité et le délinquant du criminologue italien Alessandro Baratta. On développe brièvement les principaux postulats de la thématique exposés par l'auteur dans son œuvre: Criminologie critique et critique du droit pénal: introduction à la sociologie juridico-pénale.

Mots-clés: Roit pénal, criminologie, défense social, comportement criminel.

\section{Bibliografía}

Baratta, Alessandro. Criminología crítica y crítica del derecho penal. Introducción a la sociología jurídico-penal. Buenos Aires: Siglo XXI, 2004.

Berducido Mendoza, Héctor Eduardo. El origen de la criminología científica. Acceso: 09 de julio, 2019. https:// hectorberducido.files.wordpress.com/2008/04/el-origen-de-la-criminologia-cientifica.pdf

Cermeño, Raúl. «Relaciones de la criminología con otras ciencias». Acceso: 09 de julio, 2019. http://criminologiaumg.blogspot.com/ 